\title{
AVALIAÇÃO DE METODOLOGIAS PARA ATRIBUIÇÃO DE PRESENÇAS EM ATIVIDADES PROPOSTAS NO PROGRAMA REDE DA UFSM COM BASE NA ANÁLISE MULTICRITÉRIO DE DECISÃO
}

Antônia P. S. ${ }^{1}$ - totapolly@ gmail.com

Caroline L.S. - carolinelds@ gmail.com

Andre T. K. F. ${ }^{1}-$ andretkfreitas@ hotmail.com

Natanael R. G. ${ }^{2}$ - natanael.rgomes@gmail.com

${ }^{1}$ Bolsista do Programa de Educação Tutorial em Engenharia Elétrica - UFSM

${ }^{2}$ Tutor do Programa de Educação Tutorial em Engenharia Elétrica - UFSM

Universidade Federal de Santa Maria, Centro de Tecnologia

Av. Roraima, 1000, Camobi

97105-900 - Santa Maria - Rio Grande do Sul

Resumo: Com a interrupção de atividades presenciais devido à pandemia de Covid-19, a Universidade Federal de Santa Maria decidiu adotar um regime de exercícios domiciliares especiais (REDE). Entretanto, para que os alunos obtenham aprovação nas disciplinas, continuou-se exigindo a frequência de $75 \%$ nas atividades propostas. Por outro lado, verificouse por meio de um questionário aplicado entre os docentes do curso de Engenharia Elétrica, que muitos deles ainda não definiram a forma para atribuir essas presenças à distância. Nesse contexto, este estudo é proposto à partir de uma análise de multicritério de decisão que aponta a melhor metodologia nessa situação. Após pesquisa diagnóstica sobre como outras Universidades atribuem presenças à distância, foram determinadas as opções disponíveis e os critérios para avaliação e decisão. Assim, aplicou-se um novo questionário entre docentes do curso para aplicação da análise multicritério de decisão. Conclui-se que o melhor método seria a resolução e envio de tarefas pelos discentes, após disponibilização de material de apoio com a teoria necessária.

Palavras-chave: Ensino. Frequência estudantil. Distância. Análise Multicritério.

\section{INTRODUÇÃO}

De acordo com o Guia Acadêmico da UFSM, edição de 2019, “A aprovação em qualquer disciplina de curso presencial somente poderá ser concedida ao aluno que obtiver, no mínimo, $75 \%$ de frequência nas atividades acadêmicas" (UNIVERSIDADE FEDERAL DE SANTA MARIA, 2019).

No período de interrupção das atividades presenciais devido ao novo coronavírus, a UFSM adotou o chamado Regime de Exercícios Domiciliares Especiais (REDE), com adesão facultativa para os docentes e discentes. Para aqueles que aderiram ao REDE, a portaria de regulamentação do novo regime informa: “Art. $9^{\circ}$ Em relação ao Diário de Classe, as presenças serão atribuídas em face do acompanhamento e realização das atividades por parte dos discentes" (UNIVERSIDADE FEDERAL DE SANTA MARIA, 2020). 


\section{JUSTIFICATIVA E OBJETIVOS}

Para fazer um diagnóstico da situação no curso de Engenharia Elétrica da UFSM, aplicouse um questionário entre os docentes do curso, com 17,02 \% de participação $(n=8)$. Observase que, entre aqueles docentes que estão contabilizando presenças para os alunos, isso tem sido feito com base nas participações em vídeo conferências ou entrega de listas e trabalhos, como pode ser visto na Figura 1.

Figura 1 - Resposta dos docentes à pergunta "Como você está procedendo quanto à frequência dos alunos?"

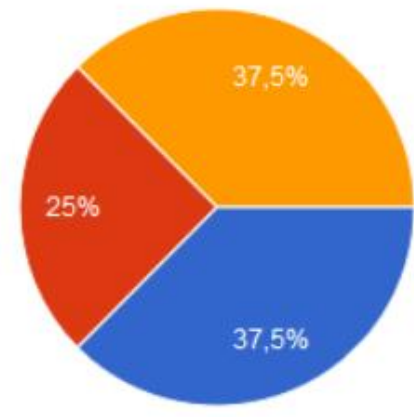

Não estou contabilizando presenças durante este período.

Observo os alunos online nas vídeos chamadas.

Considero a entrega de listas/trabalho referente ao conteúdo da aula.

Fonte: Elaborado pelo autores.

Com base nessas respostas, observa-se que é expressiva a proporção de docentes que aderiram ao REDE mas não estão contabilizando presenças. Para dar mais subsídios a essa parcela dos docentes, torna-se relevante a discussão sobre as diferentes metodologias para determinar a frequência dos alunos em atividades a distância.

Além disso, de acordo com pesquisa aplicada aos discentes do curso de Engenharia Elétrica, com participação de 22,97\% dos alunos matriculados $(n=68)$, a metodologia mais efetiva para a aprendizagem em REDE dos estudantes tem sido uma metodologia não-passiva: a realização de listas de exercícios, como pode ser visto na Figura 2.

Figura 2 - Resposta dos discentes à pergunta "Quais métodos você acha que estão sendo mais eficientes neste momento?

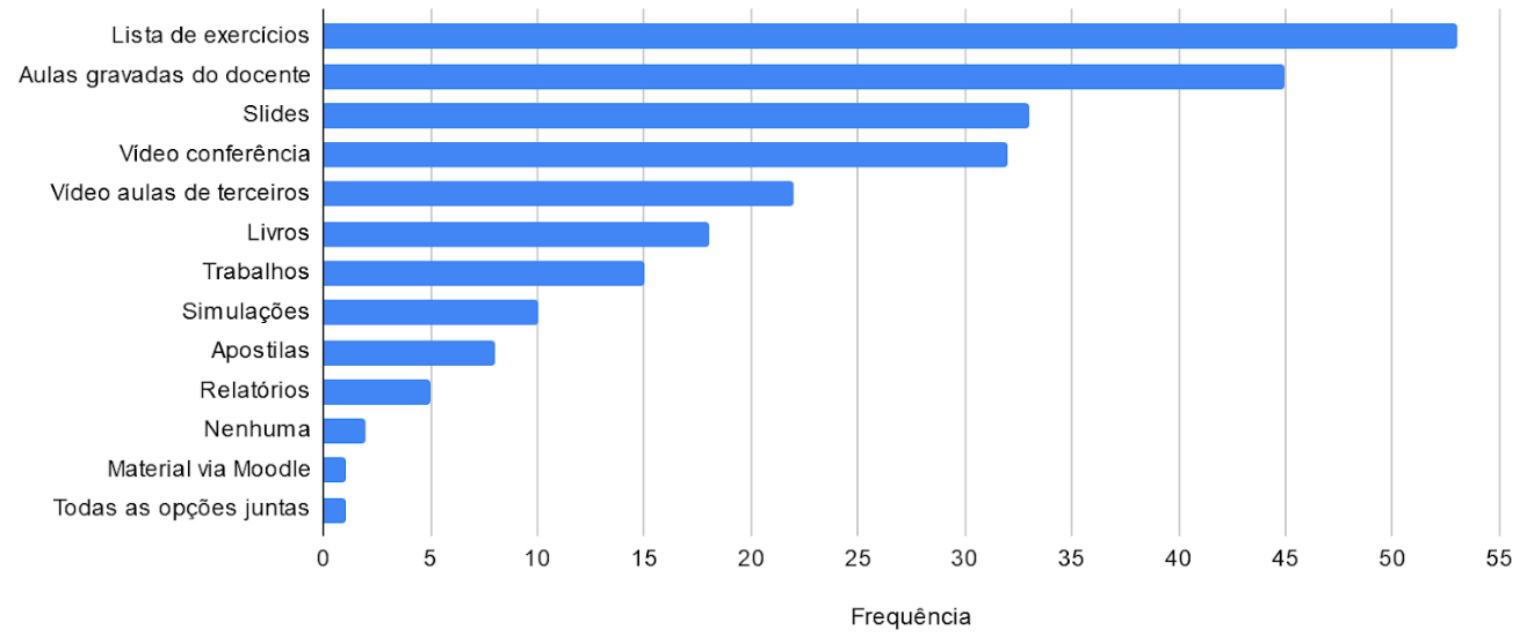

Fonte: Elaborado pelo autores. 
Assim, o objetivo deste trabalho é apontar a melhor forma para atribuir presença aos alunos, considerando-se o contexto do REDE na UFSM e também a visão dos estudantes sobre o que seria mais benéfico para seu aprendizado.

\section{REFERENCIAL TEÓRICO}

A Análise Multicritério de Decisão consiste em um conjunto de métodos objetivos para ajudar a tomar a melhor decisão entre diferentes opções, em situações cujas escolhas dependam de um conjunto de critérios (BELTON, 2002). Esse método é utilizado quando uma decisão apenas baseada em intuição deixa de ser uma solução satisfatória, principalmente devido à complexidade da situação, ou à diversidade de opiniões entre o grupo que deve tomar a decisão. Esse é o caso, por exemplo, da escolha do melhor método para atribuição de presenças em atividades propostas no REDE, pois como ilustrado pela Figura 1, existe mais de uma opção possível, e diferentes indivíduos podem considerar um método melhor que o outro.

Para implementação da Análise Multicritério de Decisão deve-se considerar que ela consiste em três etapas: na primeira, são identificados os critérios relevantes para a tomada de decisão e também as alternativas de decisão; após, deve-se atribuir valores pesos para os critérios e analisar cada uma das alternativas sob os critérios já levantados, atribuindo valores de desempenho; por fim, os resultados são obtidos ao se classificar as alternativas de forma hierárquica (SALOMON, 2010).

Para o cálculo dos valores peso de cada critério, é aplicado um questionário entre os tomadores de decisão ou especialistas com uma escala de valores para o peso de cada um dos critérios. Após, é calculada a média de todas as avaliações para cada critério, e utiliza-se a Equação (1) para calcular seus pesos individualmente $\left(\right.$ Peso $\left._{i}\right)$, sendo $m_{i}$ correspondente a média do critério $i$, e $\mathrm{m}$ correspondente à soma das médias de todos os critérios (BELTON, 2002):

$$
\operatorname{Peso}_{i}=\frac{m_{i}}{m} * 100[\%]
$$

Após, considera-se que a matriz de decisão $X_{i j}$ será composta por $i$ linhas correspondentes a cada uma das alternativas, e $j$ colunas correspondentes a cada um dos critérios. Os elementos dessa matriz indicam, portanto, o desempenho das alternativas com relação a cada um dos critérios, e eles são atribuídos com base em questionário aplicado aos tomadores de decisão. Após calculada a média de cada desempenho, procede-se com a padronização dos valores adotando o método de padronização linear, expresso na Equação (2), para cada um dos elementos da matriz, de modo que todos estejam entre 0 e 1 (BELTON, 2002):

$$
X_{i j}=\frac{X_{i j}}{X_{j, m a ́ x}}
$$

Por fim, multiplica-se cada uma das colunas da matriz $X$ pelo peso do critério correspondente, e depois soma-se os elementos de cada linha. Assim, as $i$ somas finais obtidas corresponderão a avaliação hierárquica final das alternativas correspondentes, com base nos critérios e pesos estabelecidos (SALOMON, 2010). 


\section{METODOLOGIA}

\subsection{Definição das alternativas}

Inicialmente elencou-se todos os métodos possíveis de atribuição de presenças para os alunos, que seriam: método de utilizar trabalhos sobre as aulas online para validar a presença; método de presença em aulas online; método de realizações de tarefas propostas pelo professor. Além disso, também foram analisadas suas vantagens e desvantagens.

\section{Método de utilizar trabalhos sobre a aula online para validar presença}

Essa proposta de validação de presença consiste em o aluno assistir a aula online proposta pelo professor, e após, realizar um trabalho que será sobre a matéria que o aluno acabou de receber, logo, poderá avaliar se o estudante realmente se envolveu com o conteúdo que foi exposto. Algumas vantagens podem ser citadas sobre esse método, como o fato do aluno testar o conhecimento recém obtido, além de que se o aluno tiver alguma dúvida, ela poderá ser sanada rapidamente com o professor, ou com os próprios colegas, ambos via e-mail.

Em contrapartida há também problemas adicionais que devem ser considerados, como por exemplo, se o professor não responde a dúvidas fora do período estipulado para a aula e o prazo for curto para a entrega, o aluno poderá ter dificuldades ao entregar o trabalho no prazo. Também pode-se citar o maior problema que é a falta de acessibilidade a uma internet de qualidade, o que pode fazer o estudante não conseguir acompanhar a vídeo aula, e se esta não for gravada, consequentemente não acompanhar o conteúdo fornecido pelo professor.

\section{Método de presença em aulas online}

Esse método consiste em validar a presença para quem estiver presente na aula online, inclusive há algumas plataformas que podem mostrar quanto tempo a tela do aluno permaneceu na chamada e quanto tempo ela esteve fora dela, sendo assim, o professor teria um maior controle sobre a dedicação do discente em aula. Além da presença nas aulas online, também são feitas atividades com o intuito de avaliar o conteúdo obtido pelo aluno, o que é um ponto positivo. Outros fatores positivos são o fato de que o aluno realmente terá que se manter focado em aula, pois a presença é essencial; e também que basicamente a rotina do estudante é mantida naquele horário, o que muda é apenas a aula para a modalidade a distância, pois o método de avaliação segue o mesmo.

Como desvantagem dessa cobrança de presença, pode ser citado justamente o argumento de que o método de avaliação não irá mudar, no entanto, as aulas não estão sendo realizadas da mesma maneira que eram no período presencial, pois os professores geralmente não foram capacitados a ministrar aula à distância, o que pode causar um estranhamento tanto para docente como para discente. Todos esses fatos podem acarretar em uma pior qualidade na transmissão do conteúdo a ser aprendido, sendo assim, o método de avaliação utilizado nesta situação do REDE não pode se equiparar a um presencial, pois o conteúdo terá qualidade distinta. Além disso, pode-se novamente citar que nem todos os alunos possuem condições ideais de internet para acompanhar uma aula online, o que somado ao problema anterior, faz com que o aluno aprenda ainda menos.

\section{Método de realizações de tarefas propostas pelo professor}

Neste último método é validada a presença por meio de tarefas agendadas pelo professor, ou seja, é passado um material para estudo, o aluno pode discutir sobre em um fórum, e após isso são agendadas tarefas a serem feitas sobre o conhecimento obtido, a participação valerá 
como avaliação individual. Pontos positivos acerca disso é o fato que o aluno terá o tempo que ele precisar para isso, e que poderá aprender no ritmo dele. Além de que poderá sanar suas dúvidas com outros colegas e com o professor no fórum disponibilizado. Dentre os métodos levantados, esse é o único que é assíncrono (HRASTINSKI, 2020), ou seja, o aluno tem acesso a todo material e estuda de acordo com o seu ritmo, com todos os prazos fixados somente ao final da unidade curricular.

Já os pontos negativos podem ser listados começando pelo fato de que o aluno talvez não se adapte bem a um sistema sem aulas online, afinal, ele está acostumado a frequentar aulas e depois realizar avaliações. E com esse sistema, ele teria que mudar seu método comum de aprendizagem para se acostumar com outro em que ele não está familiarizado.

\subsection{Definição dos critérios e seus pesos}

Com base no que foi exposto, foram definidos os seguintes aspectos como critérios determinantes para a escolha do melhor método de atribuição de presenças: 1) possibilidade de o aluno testar o conhecimento recém obtido; 2) prazo flexível; 3) influência da qualidade da internet; 4) quantificação do tempo dedicado para aulas; 5) mudanças na rotina do discente; 6) familiaridade dos docentes com o método.

Para definição dos pesos da análise multicritério de decisão, procedeu-se com a classificação dos critérios levantados, de 1 a 5 , sendo 5 correspondente a muito relevante, e 1 correspondente a sem relevância. Assim, aplicou-se um novo questionário a um grupo de docentes do curso de Engenharia Elétrica da UFSM ( $n=12$, com 25,53\% de participação). O resultado pode ser visto na Tabela 1 abaixo:

Tabela 1 - Definição dos pesos para cada critério de avaliação

\begin{tabular}{|l|c|c|c|c|c|c|}
\hline & $\begin{array}{c}\text { Possibilidade } \\
\text { de o aluno } \\
\text { testar o } \\
\text { conhecimento } \\
\text { recém obtido }\end{array}$ & $\begin{array}{c}\text { Prazo } \\
\text { flexível }\end{array}$ & $\begin{array}{c}\text { Influência } \\
\text { da } \\
\text { qualidade } \\
\text { da } \\
\text { internet }\end{array}$ & $\begin{array}{c}\text { Quantificação } \\
\text { do tempo } \\
\text { dedicado para } \\
\text { aulas }\end{array}$ & $\begin{array}{c}\text { Mudanças } \\
\text { na rotina } \\
\text { do } \\
\text { discente }\end{array}$ & $\begin{array}{c}\text { Familiaridade } \\
\text { dos docentes } \\
\text { com o } \\
\text { método }\end{array}$ \\
\hline $\begin{array}{l}\text { Média } \\
\text { docentes }\end{array}$ & 3,750 & 3,667 & 3,667 & 3,167 & 3,667 & 4,000 \\
\hline $\begin{array}{l}\text { Pesos } \\
\text { finais } \\
(\%)\end{array}$ & 17,11 & 16,73 & 16,73 & 14,45 & 16,73 & 18,25 \\
\hline
\end{tabular}

Fonte: Elaborado pelos autores.

\subsection{Valores de desempenho das alternativas}

Procedeu-se então com a avaliação de cada um dos três métodos, com base nos critérios já levantados. Utilizou-se o mesmo grupo amostral de docentes para avaliá-los em uma escala de 1 a 5 , sendo 5 correspondente a muito bom, e 1 correspondente a muito ruim. $O$ resultado pode ser visto na Tabela 2 (médias dos desempenhos) e Tabela 3 (desempenhos padronizados): 
Tabela 2 - Médias das classificacões dos docentes com relacão aos critérios levantados

\begin{tabular}{|c|c|c|c|c|c|c|}
\hline & $\begin{array}{c}\text { Possibilidade } \\
\text { de o aluno } \\
\text { testar o } \\
\text { conhecimento } \\
\text { recém obtido }\end{array}$ & $\begin{array}{c}\text { Prazo } \\
\text { flexível }\end{array}$ & $\begin{array}{c}\text { Influência } \\
\text { da } \\
\text { qualidade } \\
\text { da } \\
\text { internet }\end{array}$ & $\begin{array}{c}\text { Quantificação } \\
\text { do tempo } \\
\text { dedicado para } \\
\text { aulas }\end{array}$ & $\begin{array}{c}\text { Mudanças } \\
\text { na rotina } \\
\text { do } \\
\text { discente }\end{array}$ & $\begin{array}{c}\text { Familia- } \\
\text { ridade } \\
\text { dos } \\
\text { docentes } \\
\text { com o } \\
\text { método }\end{array}$ \\
\hline $\begin{array}{c}\text { Trabalhos } \\
\text { após aula } \\
\text { online }\end{array}$ & 3,083 & 3,167 & 2,917 & 2,250 & 2,833 & 3,167 \\
\hline $\begin{array}{c}\text { Presença } \\
\text { em aula } \\
\text { online }\end{array}$ & 2,083 & 2,333 & 2,917 & 2,417 & 2,583 & 2,833 \\
\hline $\begin{array}{c}\text { Realização } \\
\text { de tarefas } \\
\text { com apoio } \\
\text { de material } \\
\text { de estudo } \\
\text { (sem aula) }\end{array}$ & 3,333 & 3,417 & 2,833 & 2,417 & 3,000 & 3,333 \\
\hline
\end{tabular}

Fonte: Elaborado pelos autores.

Tabela 3 - Valores atribuídos para cada método e respectivos critérios, já padronizados

\begin{tabular}{|l|c|c|c|c|c|c|}
\hline & $\begin{array}{c}\text { Possibilidade } \\
\text { de o aluno } \\
\text { testar o } \\
\text { conhecimento } \\
\text { recém obtido }\end{array}$ & $\begin{array}{c}\text { Prazo } \\
\text { flexível }\end{array}$ & $\begin{array}{c}\text { Influência } \\
\text { da } \\
\text { qualidade } \\
\text { da } \\
\text { internet }\end{array}$ & $\begin{array}{c}\text { Quantificação } \\
\text { do tempo } \\
\text { dedicado para } \\
\text { aulas }\end{array}$ & $\begin{array}{c}\text { Mudanças } \\
\text { na rotina } \\
\text { do } \\
\text { discente }\end{array}$ & $\begin{array}{c}\text { Familia- } \\
\text { ridade } \\
\text { dos } \\
\text { docentes } \\
\text { com o } \\
\text { método }\end{array}$ \\
\hline $\begin{array}{l}\text { Trabalhos } \\
\text { após aula } \\
\text { online }\end{array}$ & 0,925 & 0,927 & 1,000 & 1,000 & 0,944 & 0,950 \\
\hline $\begin{array}{l}\text { Presença } \\
\text { em aula } \\
\text { online }\end{array}$ & 0,625 & 0,683 & 1,000 & 0,931 & 0,861 & 0,850 \\
\hline $\begin{array}{l}\text { Realização } \\
\text { de tarefas } \\
\text { com apoio } \\
\text { de material } \\
\text { de estudo } \\
\text { (sem aula) }\end{array}$ & 1,000 & 1,000 & 0,971 & 0,931 & 1,000 & 1,000 \\
\hline
\end{tabular}

Fonte: Elaborado pelos autores. 


\section{RESULTADOS}

Multiplicando cada um dos critérios pelo seu respectivo peso (já convertido para decimal), e depois somando os resultados de cada linha, correspondentes a cada um dos métodos, obtémse a Tabela 4 abaixo:

Tabela 4 - Resultados finais dos questionários pela Análise Multicritério de Decisão

\begin{tabular}{|l|c|c|c|c|c|c|c|}
\hline PESOS & 0,1711 & 0,1673 & 0,1673 & 0,1445 & 0,1673 & 0,1825 & \\
\hline & $\begin{array}{c}\text { Possibili- } \\
\text { dade de o } \\
\text { aluno } \\
\text { testar o } \\
\text { conheci- } \\
\text { mento } \\
\text { recém } \\
\text { obtido }\end{array}$ & $\begin{array}{c}\text { Prazo } \\
\text { flexível }\end{array}$ & $\begin{array}{c}\text { Influên- } \\
\text { cia da } \\
\text { qualida- } \\
\text { de da } \\
\text { internet }\end{array}$ & $\begin{array}{c}\text { Quantifica- } \\
\text { ção do } \\
\text { tempo } \\
\text { dedicado } \\
\text { para aulas }\end{array}$ & $\begin{array}{c}\text { Mudan- } \\
\text { ças na } \\
\text { rotina } \\
\text { do } \\
\text { discente }\end{array}$ & $\begin{array}{c}\text { Familiari- } \\
\text { dade dos } \\
\text { docentes } \\
\text { com o } \\
\text { método }\end{array}$ & SOMA \\
\hline $\begin{array}{l}\text { Trabalhos } \\
\text { após aula } \\
\text { online }\end{array}$ & 0,158 & 0,155 & 0,167 & 0,145 & 0,158 & 0,173 & 0,956 \\
\hline $\begin{array}{l}\text { Presença } \\
\text { em aula } \\
\text { online }\end{array}$ & 0,107 & 0,114 & 0,167 & 0,135 & 0,144 & 0,155 & 0,822 \\
\hline $\begin{array}{l}\text { Realiza- } \\
\text { ção de } \\
\text { tarefas } \\
\text { com apoio } \\
\text { de material } \\
\text { de estudo } \\
\text { (sem aula }\end{array}$ & 0,171 & 0,167 & 0,162 & 0,135 & 0,167 & 0,183 & 0,985 \\
\hline
\end{tabular}

Fonte: Elaborado pelos autores.

Como é possível observar na última coluna, na opinião dos docentes o melhor método para atribuição de presenças em atividades efetuadas a distância é a realização de tarefas com apoio de material de estudo (sem aula). O segundo melhor método seria a realização de trabalhos após aula online, gravada ou em videoconferência. Já o método pior avaliado seria a contabilização de presenças em aulas online, por videoconferência. 


\section{CONSIDERAÇÕES FINAIS}

Conclui-se que ao se comparar a Figura 2 com os resultados da análise de multicritérios apresentados na Tabela 4, comprova-se que o melhor método para validar a presença é através de listas de exercícios com um material de apoio. Ainda, em uma análise mais minuciosa, podese perceber que uma boa parcela dos alunos acha mais eficaz estudar pelas aulas gravadas do professor. Sendo assim, um método para beneficiar a todos poderia ser da cobrança de exercícios para validar presenças e, ao mesmo tempo, deixar como material de estudo também algumas aulas gravadas, caso o aluno prefira estudar por esse meio. Por conseguinte, é imprescindível fornecer aos docentes capacitação para a produção de materiais de apoio para atividades semelhantes aquelas propostas em REDE, isto é, atividades a distância, uma vez que isso foge do formato de aula tradicional.

Uma das limitações desse estudo é que considerou apenas a opinião dos docentes. Assim, um próximo passo seria considerar também a opinião dos alunos na escolha do método para atribuir presenças e, então, comparar os resultados. Além disso, considerando a diversidade de opiniões entre grupos, também surge como possibilidade do desenvolvimento de um programa open-source capaz de receber como entradas as opiniões de docentes e discentes e que realize os cálculos da análise multicritério de decisão. Assim, seu resultado poderia ser empregado para decidir o melhor método de acordo com o grupo em questão, que poderia ser desde uma Universidade inteira, até grupos menores como turmas de disciplinas. 


\title{
REFERÊNCIAS
}

BELTON, Valerie; THEODOR, Stewart. Multiple criteria analysis: an integrated approach. Berlim: Springer Science \& Business Media. 2002.

HRASTINSKI, Stefan. Asynchronous and Synchronous E-Learning. Educause Quarterly, Louisville, n. 4., p. 51-55, 2008.

SALOMON, V. A. P. Anality hierarchy process. In: MARINS, F. A. S; PEREIRA, M. dos S.; BELDERRAIN, M. C. N.; URBINA, L. M. S. (ORG). Métodos de Tomada de Decisão com mútilplos critérios, aplicações na indústria aeroespacial. São Paulo: Blucher Acadêmico, 2010.

UNIVERSIDADE FEDERAL DE SANTA MARIA. Guia Acadêmico da UFSM: Edição 2019. Santa Maria, 2019.

UNIVERSIDADE FEDERAL DE SANTA MARIA. Instrução Normativa N. 02/2020/PROGRAD. Santa Maria, 2020.

\section{EVALUATION OF METHODOLOGIES TO REGISTER ATTENDANCE IN ACTIVITIES PROPOSED IN UFSM'S REDE USING MULTICRITERIA DECISION ANALYSIS}

\begin{abstract}
Due to the interruption of presential activities because of the Covid-19 pandemics, the Universidade Federal de Santa Maria has adopted a home activities special regime (REDE). However, in order to obtain approval on subjects, students still need to fulfill the requirement of $75 \%$ of activities' attendance. On the other hand, a survey answered by professors of the Bachelor of Electrical Engineering showed that many of them have not yet decided how to register students' attendance in these distance learning activities. In this context, this study makes a multicriteria decision analysis to indicate the best attendance tracking methodology for this situation. After researching how other universities register students' attendance in distance learning activities, the methodologies available and the criteria needed for decision making were determined. Therefore, a new survey was applied among professors in order to use the multicriteria decision analysis. It was possible to conclude that the best methodology is students solving exercises and sending them to professors, using available support materials with the needed theory.
\end{abstract}

Keywords: Teaching. Student attendance. Distance. Multicriteria analysis. 